\title{
Building Bridges to a Better Engineering Design Education Experience
}

\author{
Dr. Sean Maw \\ Associate Professor, Department of Mathematics, Physics and Engineering \\ Mount Royal University, Calgary, Alberta \\ smaw@mtroyal.ca
}

\begin{abstract}
In the Fall 2010 semester, Mount Royal University's Engineering Transfer Program ran its first version of a new Engineering Design course that combined two term courses into one. The course consisted of integrated Technical Writing, Technical Drawing and Sketching, and Design elements. The Design element, consisting of three hours/week of in-class activities, focused on the introduction of elements of the design process, activities to expose students to the real-life aspects of each stage of the process, and a term project that brought all elements of the course together in one real-life application. The term project was the (re)design of a pedestrian footbridge on the Mount Royal (MRU) campus. The existing bridge, approximately $3.5 \mathrm{~m}$ long by $2 \mathrm{~m}$ wide, spans a manmade gulley and joins two parts of a pedestrian walkway. Relevant MRU grounds staff were involved in the project as clients and more than 100 students worked in small groups (3-5 members each) to design and then build a $1 / 3^{\text {rd }}$ scale model of their bridge design using a somewhat constrained materials list and basic wood shop facilities. Components of the project were also integrated with other courses in the curriculum, such as Statics. This paper details the logistics of the course and of the project, as well as the lessons learned in terms of things that worked well and those that did not. Overall, the project was deemed a solid success based on feedback from students, clients and instructors. This kind of project could also be carried out at other Canadian university campuses with minimal alterations.
\end{abstract}

\section{Introduction}

In the Fall of 2010, Mount Royal University's Engineering Transfer Program rolled out a new singlesemester engineering design course called ENGR 1271 (Engineering Design and Communication) to track evolving curriculum at the University of
Calgary's Schulich School of Engineering, the main destination for MRU Engineering transfer students. ENGR 1271 combined the content of two single semester engineering design courses that had been previously taught at MRU and at the Schulich School. This included an applied term project component.

ENGR 1271 integrates engineering design, technical writing, and drawing/sketching curriculum. Learning objectives include the development of basic competency in technical drawing and sketching (e.g. isometric and multi-view) as well as technical writing skills and a working familiarization with the engineering design process. It is also the intent of the course to show the relevance of course work in reallife engineering design applications. To that end, the term project was chosen to be the (re) design of an actual pedestrian footbridge on campus.

While the course was heavy on workload, the feedback from students was largely very positive and the enthusiasm for the work was evident. This paper presents many of the logistical details of the course and some of the resulting outcomes so that other engineering educators may learn from these examples and experiences, and so that ENGR 1271 may continue to be improved in the future.

\section{Course Description}

This section describes ENGR 1271 in detail so that a learning context can be established by the reader.

\subsection{Logistics}

Approximately 115 students were enrolled in ENGR 1271 spread over 5 class sections varying in size from 12 to 26 students. Each student attended a 3 hour design lab each week, as well as a 1.5 hour technical writing class and a 1.5 hour technical drawing and sketching class. The design labs ran from 9 am to noon on Mondays, Wednesdays and Fridays (MWF), and from $2 \mathrm{pm}$ to $5 \mathrm{pm}$ on Mondays and Wednesdays. Writing and drawing classes were scheduled around 
the design labs in the same room, an open classroom with 6 tables for up to 5 students each.

One staff person taught all of the drawing and sketching, while various staff taught technical writing due to the loss of the primary writing instructor early in the course due to injury. The design classes were taught by two instructors (one with three sections, and the other with two), while a shop manager supported both of them for a 6-week period in the latter half of the course. The shop manager provided an orientation to the shop facilities, supervised said facilities, and assisted students in building scaled bridge prototypes. The shop manager also built $1 / 3^{\text {rd }}$ scale bridge abutment models so that students could display their bridge prototypes in a suitable context.

Each student had 12 full weeks of design labs and technical writing and drawing classes.

In terms of class textbooks, two were used. One was for technical writing [1] while the other combined drawing and sketching, and engineering design [2]. This second text was a custom textbook made possible by John Wiley \& Sons, Inc. It combined specific chapters of two popular texts, [3] and [4], thereby reducing the total cost to students.

Most students in the course were in their first term of engineering education, although $\approx 15 \%$ were in their third term. Most students had high school averages in the range of $65-75 \%$. This program tends to attract large numbers of rural Alberta students, recent immigrants, and mature students, as well as students who completed high school slightly below the cut-off averages for programs such as those at the University of Calgary.

Students in ENGR 1271 were divided into groups of 4-5 in the second week of the course for the purpose of project work for the rest of the term. They performed mostly individual work for the drawing and writing course components.

Deliverables over the term included: five (5) technical writing assignments, five (5) sketching and drawing assignments, five (5) design assignments, a logbook, a group oral presentation and bridge design prototype, and a group final recommendation report.

\subsection{Drawing and Sketching Component}

Each week of the term, students received instruction in technical drawing and sketching for 1.5 hours using pencils and paper. Approximately every other week students had an assignment or quiz on these topics.

Topics covered over the term included: line types and weights, proportioning, isometrics, multi-views, projections, auxiliary views, dimensioning, missing lines and views, motion and connectivity, sectioning, and working drawings.
Students were also expected to regularly sketch in their logbooks in support of the project, and they were evaluated on how well they did so. In two of their design assignments they were expected to show sketches or drawings of their design concepts, and part of the final drawing assignment was actually the working drawings for their bridge design in the final recommendation report.

Students found the volume of work in this portion of the course quite demanding.

\subsection{Technical Writing Component}

Each week of the term, students received instruction in writing technical documents, as well as in writing style and grammar, for 1.5 hours. Approximately every other week students had an assignment or quiz on these topics alternating with the drawing and sketching assignments.

Topics covered over the term included: project proposals, instructional memos, technical descriptions, professional ethics, presentations and recommendation reports. As well, in terms of style and grammar, we covered the use of commas, apostrophes, parallelism, pronoun referencing, and confusing word pairs e.g. affect/effect. In addition to the technical writing assignments, students were evaluated on their style and grammar in every design assignment. As it was, most of the writing assignments either focused on the project as the main topic or they were highly applicable to a design assignment e.g. presentations.

Most writing classes featured a period of time focusing on a style/grammar topic, some exercises related to the material, some instruction on the upcoming writing assignment topic, and then an exercise related to that topic. Grammar exercises were completed in informal (non-project) groupings on a mildly competitive basis on what were often humorous examples. Combined with the more applied exercises and the assignments they supported, the activities engendered a reasonable level of acceptance of the technical writing topic matter, which is often a challenge in this course.

\subsection{Engineering Design Component}

Each week of the term, students attended a 3 hour design lab/class where they would typically receive instruction in engineering design followed by an activity applying the new material, and then project time for applying the material to the design project.

Over the course of the term, students were first introduced to the design process and then each step was sequentially revisited, in depth. The major topics covered included: an overview of the design process, 
forming teams, logbooks, Gantt charts, budgeting, problem familiarization/characterization, problem statements, criteria and constraints, functionality, idea/solution generation techniques, evaluation using analysis, testing, and research, shop orientation, design selection, prototyping, detailed design, optimization, presentations, and recommendation reports.

The centerpiece of the course was to be the design project. We wanted something applicable to the real world that would illustrate all of the concepts being taught, yet something simple enough that the students could do a credible job on it. We also wanted the project to tie in with material from other courses, if possible. We went with the redesign of a simple footbridge on MRU's campus that would need replacing within a few years (see Figure 1 below).

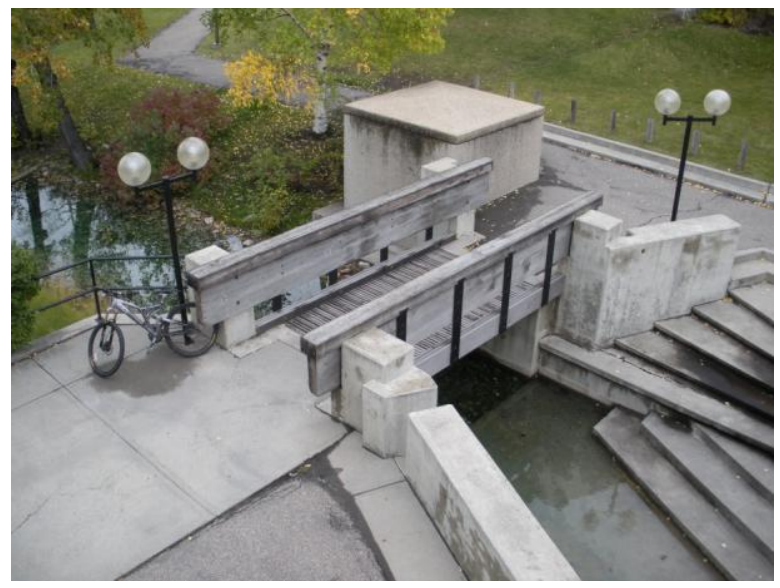

Figure 1. Existing MRU footbridge

Entitled "Bridging the Gap", the project tasked the students with designing a replacement for the existing bridge and producing a $1 / 3^{\text {rd }}$ scale prototype of their design. Students were constrained to using wood for major structural components as well as the existing concrete abutments for support. Shortly after the start of the project, we did allow for some minor specified alterations to the abutments, as well as the use of nonwooden materials for non-structural components.

Mostly through the middle of the term, student groups completed five (5) design assignments, all of which fed directly into specified components of the final recommendation report. The first assignment dealt with problems statements, scope, criteria and constraints, and problem descriptions. The second assignment looked at pairwise comparison charts (criteria), design requirements and functionality. The third assignment dealt with alternative conceptual solutions, while the fourth assignment required the students to show how they had evaluated alternative solutions using research, testing and statics analysis.
The fifth and only individual design "assignment" was, in fact, a test covering all of the lecture material from the term. In addition, each group had to prepare an oral presentation of their design, a prototype, and a final recommendation report. Each individual student also handed in their logbooks at the end of the term.

\section{Coursework Evaluation}

For the technical writing course component, this consisted of four individual assignments plus one quiz, each worth $6 \%$. For the drawing/sketching, this consisted of four individual assignments each worth $6 \%$ plus a summary quiz worth $3 \%$ and one drawing in their group's final report also worth $3 \%$. For the design component, a student's logbook was evaluated for variety, quality and quantity of entries for $4 \%$ of their course grade. The group's presentation and prototype collectively counted for $7.5 \%$ while the final recommendation report was worth $8.5 \%$. The four group assignments during the term, and the individual design quiz, were each worth $4 \%$. To reduce the workload associated with the final report, a content template was provided which allowed for the easy inclusion of revised material from the term's assignments. As such, the final report preparation was as much editing as it was original composition.

Marking criteria were always provided on each assignment. For the design portion of the course, which was almost entirely group-based, if a student missed a class for a valid (e.g. medical) reason, there was no penalty. However, even for a valid reason, if there was a second such absence, there was a penalty and a third such absence resulted in an automatic failing grade in the course, regardless of the reason for the absence. For the other portions of the course, a similar principle applied to assignments i.e. missing one (for a valid reason) did not result in a penalty as marks were simply redistributed among the remaining assignments. However, if another assignment was missed, this resulted in an automatic F. Students had to pass each of the three parts of the course, independently, to pass the course.

In the case of three project groups, at least one student withdrew before the withdrawal deadline, leaving a smaller team behind to finish the project. Teams of three were given the option of continuing as they were, with a reduced workload of working drawings for the final report. In one case, only two students were left and they were redistributed to other groups that wanted their assistance.

As a final modifier to an individual student's design mark, each group was given $100 \% \mathrm{x}$ the number of group members. Group members then 
distributed these weightings, by consensus, with respect to the group project components i.e. all of the design marks for the course minus the $4 \%$ for the logbook. If consensus could not be reached, the instructor made a judgement on the matter based on team contracts established at the start of the term, documentation in logbooks, and other evidence such as email correspondence. For example, in a group of four, the group's $400 \%$ could be distributed $110 \%$ for a very hard-worker, $105 \%$ for a leader, $90 \%$ for someone who didn't do as much as the others, and $95 \%$ for someone whose work was of a consistently lower quality. These percentages would then be multiplied by the marks that the group achieved in the group assignments, presentation, prototype and final report, to arrive at an individual's design mark.

\section{Discussion}

All of the decisions made in designing ENGR 1271 were made with intent against pedagogical criteria. In many cases, the outcomes were favourable, as had been hoped. In other cases, better decisions could probably be made in the future.

Overall, the project topic seemed to work very well. Enthusiasm among students was typically very high, and the quality of the results (such as prototypes) was also typically quite high e.g. see Figure 2 below. Integration of course material worked well e.g. design assignments and the final drawing assignment fed into the final report. Drawing/sketching was a component of two design assignments, and technical writing was evaluated on all design assignments. Two of the technical writing assignments were directly applied to the project. As well, the inclusion of a simple statics analysis in the fourth design assignment brought the Statics course into focus in a very applied manner.

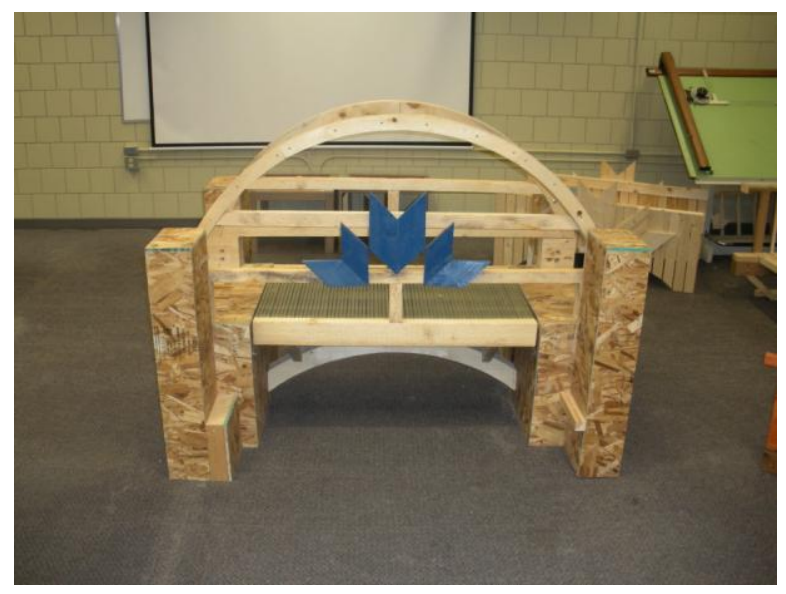

Figure 2. Student design on model abutments
With no Teaching Assistants, a maximum section size of 25 was manageable but challenging. The distribution of classes over MWF was good, as sessionals could focus on 1-2 days of teaching a week. However, this did create bottlenecks in the shop where a maximum of 30 students could be present at any given time. Having a design lab each day of the week could be a better model, although the holiday schedule throughout the term must also be considered i.e. each section must have the same number of classes over the term, independent of when holidays may fall.

Shop activity was highly concentrated in the two weeks preceding the presentations. With an initial shop set-up and orientation week, and another week for more proactive groups to get going and order materials, it may work better to have a shop manager full-time for $4 \frac{1}{2}$ weeks rather than part-time (at 3 days/week) for 6 weeks.

The mix of writing, drawing and design in the course worked well. However, care must be taken to ensure that the workload is not overwhelming on any given week i.e. stagger and pace assignments in a coordinated way, and that the workload is proportional to the course marking weightings of the 3 disciplines.

In terms of organizing instruction, it is feasible to have instructors teach writing, drawing and design so that a given section has the same instructor for every component. Advantages in terms of integration of material and adaptability to student needs would be expected. However, it would also be more challenging to locate appropriately skilled sessional instructors and having one instructor across all sections, by discipline, offers the advantage of consistent evaluation and grading between sections, which can be very important in transfer programs.

It is also important that all instructors for the course have a similar pedagogical philosophy towards learning objectives and assessment rigour. Key points include how "effort" is treated versus the quality of performance. With clear and thoughtful evaluation criteria, design can be taught and evaluated rigorously without having to be capricious.

The choice of project topic (bridge design) worked out exceedingly well for the following reasons. The project was realistic. Indeed, we had an on-site client (Mr. Shane Williams, MRU's Grounds Manager) who was available to spend a class with each section both at the start of the term and at the end of the term for the presentations. This client involvement was vital. He was also available for questions during the rest of the term, for one designated person in each group. That also worked out well. The project site was on campus and was therefore highly accessible to the students. This was very important for the problem familiarization phase. As well, this specific type of 
bridge was neither too trivial (e.g. a garden bridge) nor too challenging. The existing concrete abutments (see Figure 1 on previous page) provided pedagogically valuable constraints that also limited the scope of the project. The choice by the instructors to limit building materials both for the final design and for the prototypes was also important, but perhaps more controversial than any other decision made. The restriction on materials limited the possible costs to the shop and to the students. However, it also restricted design freedom which some took as a restriction on creativity. This was pedagogically valuable as the wiser students realized that this restriction actually created opportunities for innovation. It also allowed everyone to make use of wooden beam selection tables in the fourth design assignment which was a valuable learning experience and a novel tie-in to Statics. One thing that might have worked better was to go with $1 / 4$ scale prototypes. This would have reduced material use and cost, as well as assembly time and portability issues (the shop was two floors below and quite far from the main classroom).

In terms of textbook choices, the integration of the design [3] and graphics [4] textbooks in [2] worked very well from the perspective of the instructors. However, compliance on weekly reading homework was typically poor unless the students absolutely needed the material to complete an assignment or prepare for a text/quiz. The few students that kept up with the readings did seem to find value in them.

In terms of technical writing, challenges included incoming skill levels for writing composition and grammar. Skill levels were typically not strong. During the term, grammar and style was taught using humour, which helped with palatability. The consistency of application of clear evaluation criteria was also another challenge in this area.

For the drawing and sketching, students were assumed to arrive with no specific skills. As such, there was much to cover, and practice is important in this discipline since it is not something that students typically perform daily otherwise (as opposed to writing, for example). As such, a high volume of work was assigned and this provided both a managerial and a motivational challenge. One must also keep in mind that if demands are set too high, this can foster cheating or plagiarism. Fortunately, very few occurrences of this behaviour were found.

In terms of design, one instructor taught three sections while another taught two sections. Initially, each instructor marked his own class' assignments. However, having one instructor mark an assignment across all sections resulted in better evaluation consistency for the last few assignments, and fewer concerns among students between classes/instructors.

Looking closely at some of the design content, group formation is a natural place to start. Most students did not know any other students in the class as this was their first term in engineering. As such, we went through a "speed dating" exercise where each student had a chance to talk with/interview everyone else in the class, one on one. Then the students were able to select up to 3 students that they really wanted to be in a group with, and up to one "undesirable". Instructors then formed groups under these constraints without too much difficulty, promising at least one "preferred" teammate and no undesirables. Prior to the "speed dating" exercise, students completed online personality tests and skill inventories to see examples of bases for group formation. Giving the students a strong say in who they would be working with seemed to give greater buy-in to the group formation process.

Quite possibly the weakest element of the curriculum in terms of impact on student performance was the set of activities focused on planning (work breakdown structures, budgets, Gantt charts, etc.). These elements need to be revisited regularly to see which initial assumptions are incorrect in the planning process. We did this briefly mid-term, but if marks are not attached to such exercises they may either be cursorily done or not done at all. These documents were, nevertheless, required as an appendix in the final report.

Over the first few weeks after the groups were formed, groups had to carry out short and simple design exercises e.g. make as tall a free-standing structure as you can, given these (limited) materials. This provided an iterative way to apply the newly introduced design process, and to focus on specific steps such as identification of key criteria and constraints, and how to work with these concepts. The iteration of these short and fun design opportunities was important, as the students often applied prior lessons learned to the latest design challenge. Good carry-over was also observed to the bridge design project.

Having the project client come in for a class "interview" was also extremely beneficial, especially when the client's answers to key questions tended to drift over time as the client's understanding of the problem changed. This was an excellent learning opportunity relevant to the real world, showing the malleability of real design problems.

Activities focused on developing a concise and pithy problem statement were also valuable, as first year students tend to start with vague and drawn out compositions. Peer critiques after a few exemplars were given, appeared to help students develop the 
skills to write effective statements. Some role playing was also carried out where the instructor acted as a client for a poorly framed problem.

On criteria and constraints, the simple problem of picking the "best" mode of transportation from Calgary to Toronto served to very effectively illustrate key concepts such as do we have all the relevant criteria e.g. environmental impact; what about limits (constraints) on these parameters such as travel time; are they all equally important measures of success (criteria weightings); and how accurate can we be in assessing a given transportation mode against a given criterion or constraint e.g. safety? This example was revisited throughout the term to illustrate new nuances with criteria and constraints, including final decision matrices, detailed design and optimization.

Functionality was effectively explored using the black box model, enumeration, reverse engineering and verb-object pairings. The idea of finite state machines complemented the black box discussion and also introduced the idea of professional responsibility in terms of knowing how a device might react under all conceivable conditions.

A wide variety of amusing and thought-provoking approaches and exercises were used to illustrate the generation of alternative conceptual solutions including: brainstorming, morph charts, synectics and force fitting, verb manipulation, and analogy or metaphor. Once students released their inhibitions, some excellent ideas were proposed. All exercises focused on their group project, to maintain motivation.

In terms of evaluating alternative solutions, students were given simple research exercises to complete in a contest format. As well, they were given a simple testing exercise to illustrate the challenges in doing valid testing of concepts. They were given a set amount of cardboard and were challenged to discover what beam cross-sectional qualities provide strength for supporting distributed loads. On the take-up to the activity, the idea of moments of inertia with regards to beam bending was introduced and clarified, which motivated this concept for their Statics class the following week.

Projects such as these also provide opportunities for program promotion. Local newspapers picked up on the project and covered it [5], interviewing students and photographing particularly attractive designs.

\section{Conclusions and Future Directions}

For a first effort, ENGR 1271 went very well in terms of student learning, interest and achievement. The project of redesigning a local campus footbridge provided a very rich learning opportunity. While many of the decisions made seemed to support student learning, there were a few areas where optimization could occur.

The demand on shop time was intense leading up to the presentations of the prototypes. A full-time shop manager for a shorter period would be more useful than a part-time shop manager over a longer period since most students are only ready to get into the shop shortly before their presentation. In the same light, it would be useful to try having one lab class each day of the week instead of having two labs each on Mondays and Wednesdays.

Planning documents should be revisited, for marks, midway through the term to close the loop on planning and to emphasize their importance and value.

This same project can easily be repeated in the coming year, with such changes. However, it may be advisable to try a different project topic for a couple of years after that to avoid "cookie cutter" solutions based on the work of previous cohorts. If and when the bridge is revisited in future years, it would be advised to try a $1 / 4$ scale for prototypes.

\section{Acknowledgements}

Several individuals played key roles in delivering ENGR 1271 including Mr. Clark Beatty (Shop Manager), Ms. Kaitlin Ford and Mr. Shoaib Nasir (Technical Writing Sessionals), Dr. Mark Hagel, P.Eng. (Design Sessional), Mr. Patrick Hurst (Drawing/Sketching Sessional), Dr. Janice MillerYoung, P.Eng. (Assoc Professor) and Mr. Shane Williams (MRU Grounds Manager). They were all important players in the success of the course.

\section{References}

[1] D. Beer and D. McMurrey, A Guide to Writing as an Engineer, $3^{\text {rd }}$ Edition, John Wiley \& Sons, Inc., USA, 2009.

[2] ENGR 1271 Engineering Design and Communication I, Wiley Custom Learning Solutions, John Wiley \& Sons, Inc., USA, 2009.

[3] C. L. Dym and P. Little, Engineering Design: A ProjectBased Introduction, $3^{\text {rd }}$ Edition, John Wiley \& Sons, Inc., USA, 2009.

[4] J. Leake and J. Borgerson, Engineering Design Graphics: Sketching, Modeling and Visualization, John Wiley \& Sons, Inc., USA, 2008.

[5] S. Noble, Students have chance to make mark on campus, MRU Face Time, Calgary, December 9, 2010. 